UDK $517.551: 517.535$

\author{
M. M. Pahirya*,** \\ * Uzhhorod National University, \\ Uzhhorod 88000 \\ ** Mukachevo State University, \\ Mukachevo 89600. E-mail: pahirya@gmail.com
}

\title{
Representation of a one class function of two variables by bicontinued fractions
}

Нехай функція $u(z, w)=f(z) h(w)$ визначена на компакті $\mathbf{K}=\mathbf{Z} \times \mathbf{W} \subset \mathbb{C}^{2}$. Досліджується задача зображення функцій такого класу добутком ланцюгових дробів по кожній змінній, який називають біланцюговим дробом. В роботі доведено нові властивості обернених похідних Тіле та коефіцієнтів розвинення складеної функції однієї змінної в ланцюговий дріб Тіле і провильний ланцюговий $\mathbf{C}-$ дріб. Зокрема доведено, що якщо $D(z ; g)$ розвинення функції ланцюговий дріб Тіле, то розвинення функціх $\bar{g}(z)=C g(z), C=$ const, має вигляд $D(z ; C g)=C D(z ; g)$. Крім того показано, що обернені похідні Тіле функції $\check{g}(z)=g(C z)$ визначаються за формулами ${ }^{(2 k)}(g(C z))=\left.{ }^{(2 k)} g(v)\right|_{v=C z},{ }^{(2 k-1)}(g(C z))=\left.C^{-1} \cdot{ }^{(2 k-1)} g(v)\right|_{v=C z}, k \in \mathbb{N}$.

Отримані властивості обернених похідних та ланцюгових дробів разом із відомими їх властивостями дозволяють обгрунтувати можливість зображення функцій двох змінних розглянутого класу біланцюговими дробами Тіле та біланцюговими С-дробвами, встановити області збіжності та рівномірної збіжності отриманих зображень.

В якості ілюстрації розглянуто зображення біланцюговими дробами двох функцій $u_{1}(z, w)=(\delta+\beta z)^{\alpha} \operatorname{tg}(\varepsilon+\gamma w)$, де $\alpha \in \mathbb{C} \backslash\{\mathbb{Z}\}, \beta, \gamma, \delta, \varepsilon \in \mathbb{C} \backslash\{0\}$ та $u_{2}(z, w)=e^{\alpha z} \ln (\beta+\gamma w)$, де $\alpha, \beta, \gamma \in \mathbb{C} \backslash\{0\}$. Доведено, що отримані зображення біланцюговими дробами функції $u_{1}$ збігаються до функції в області $\mathbb{G}_{1}=\left\{z \in \mathbb{C}:\left|\arg (\delta+\beta z)-\arg \left(\delta+\beta z_{*}\right)\right|<\pi\right\} \times \mathbb{C} \backslash\{\gamma w \neq$ $\left.\frac{k \pi}{2}-\varepsilon, k \in \mathbb{Z}\right\}$ i на довільному компакті $\mathbf{K} \subset \mathbb{G}_{1}$ біланцюгові дроби збігаються рівномірно. Аналогічно, в області $\mathbb{G}_{2}=\mathbb{C} \times\left\{w: w \in \mathbb{C} \backslash\{-\beta / \gamma\},\left|\arg (\beta+\gamma w)-\arg \left(\beta+\gamma w_{*}\right)\right|<\pi\right\}$ побудовані біланцюгові дроби збігаються до функції $u_{2}$. На довільному компакті $\mathrm{K} \subset \mathbb{G}_{2}$ біланцюгові дроби будуть збігатися рівномірно. Запропонована в даній роботі методика природньо поширюється на випадок функцій трьох та більше змінних, які належать до аналогічних класів.

Ключові слова: ланчюгові дроби, біланцюгові дроби, функцї̈ двох комплексних змінних, зображення функиій

Функция $u(z, w)=f(z) h(w)$ определена на компакте $\mathbf{K} \subset \mathbb{C}^{2}$. Исследуется задача представления функций такого класса произведением двух непрерывных дробей, которое именуется бинепрерывной дробью. Доказаны некоторые свойства обратных производных Тиле, непрерывных дробей Тиле и правильных С-дробей. Показана возможность представления функций такого класса бинепрерывными дробями. Рассмотрены примеры, указаны области сходимости и равномерной сходимости полученных бинепрерывных дробей к функции. 
Ключові слова: непрерывные дроби, бинепрерывные дроби, функиии двух комплексных переменных, представление функиий

Let function $u(z, w)=f(z) h(w)$ be defined on the compact set $\mathbf{K} \subset \mathbb{C}^{2}$. We study the problem of representation of functions of this class by the product of two continued fractions, which is called a bicontinued fraction. Some properties of Thiele reciprocal derivatives, Thiele continued fractions and regular $\mathbf{C}-$ fractions are proved. The possibility of representation of functions of this class by bicontinued fractions is shown. Examples are considered, domains of convergence and uniform convergence of obtained bicontinued fractions to the function are indicated.

Key words: continued fractions, bicontinued fractions, functions of two complex variables, representation of functions

MSC2010: PRI 30B70, SEC 30E05, 30E10

\section{Introduction}

The functions of one real or complex variable can be approximate polynomials [1, 2, 3], splines [4], rational functions or Padé approximants [5, 6, 7]. Continued fractions are used to approximate functions too $[8,9,10]$. Methods of approximation functions of one variable are generalized to functions of many variables [14, 15], functionals and operators $[16,17]$.

The Thiele formula is an analogue of a Taylor formula in the theory of continued fractions. The Thiele formula has advantages over other methods of expansion of a function in continued fractions since coefficients of expansion are determined by reciprocal derivatives of a function $[11,12,13]$.

Bicontinued fraction is a new concept that is introduced in this article. Let $u$ be a function of two variables of the form $u(z, w)=f(z) h(w)$. The problem of a function approximation by bicontinued fractions investigated in the paper. The new properties of Thiele continued fractions and Thiele reciprocal derivatives are proved. These properties are used when representing functions by bicontinued fractions.

\section{Approximation of functions by continued fractions}

Note that in addition to the set of natural numbers $\mathbb{N}$, we also use the following sets of integer numbers $\mathbb{N}_{0}=\mathbb{N} \cup\{0\}$ and $\mathbb{N}_{2}=\mathbb{N} \backslash\{1\}$.

The necessary concepts of the theory of continued fractions [9] will be given below.

Definition 1. A continued fraction is an ordered pair $\left\langle\left\langle\left\{a_{n}\right\},\left\{b_{n}\right\}\right\rangle,\left\{f_{n}\right\}\right\rangle$, where $\left\{a_{n}: a_{n} \in \mathbb{C}, a_{n} \neq 0, n \in \mathbb{N}\right\},\left\{b_{n}: b_{n} \in \mathbb{C}, n \in \mathbb{N}_{0}\right\}$ are sequences of complex numbers, and $\left\{f_{n}: f_{n} \in \overline{\mathbb{C}}=\mathbb{C} \cup\{\infty\}, n \in \mathbb{N}_{0}\right\}$ is a sequence in the extended complex plane defined as follows: $f_{n}=S_{n}(0), n \in \mathbb{N}_{0}, S_{0}(w)=s_{0}(w), S_{n}(w)=S_{n-1}\left(s_{n}(w)\right), n \in \mathbb{N}$, $s_{0}(w)=b_{0}+w, s_{n}(w)=a_{n} /\left(b_{n}+w\right), n \in \mathbb{N}$. 
The infinite continued fraction of form

$$
b_{0}+\frac{a_{1}}{b_{1}+\frac{a_{2}}{b_{2}+\ddots \quad \frac{a_{i}}{b_{i}+\ddots}}},
$$

we shall denote by one of the symbols $b_{0}+\frac{a_{1}}{b_{1}}+\frac{a_{2}}{b_{2}}+\ldots+\frac{a_{i}}{b_{i}}+\ldots$, or $b_{0}+\mathbf{K}_{i=1}^{\infty}\left(a_{i} / b_{i}\right)$, or $b_{0}+\mathbf{K}\left(a_{i} / b_{i}\right)$. Similarly, the finite continued fraction, $n$th approximant of infinite continued fraction

$$
b_{0}+\frac{a_{1}}{b_{1}+\frac{a_{2}}{b_{2}+\cdot a_{n}}},
$$

may be denoted by $b_{0}+\frac{a_{1}}{b_{1}}+\frac{a_{2}}{b_{2}}+\cdots+\frac{a_{n}}{b_{n}}$, or $b_{0}+\mathbf{K}_{i=1}^{n}\left(a_{i} / b_{i}\right)$.

Definition 2. Continued fractions $b_{0}+\mathbf{K}\left(a_{i} / b_{i}\right)$ and $d_{0}+\mathbf{K}\left(c_{i} / d_{i}\right)$ with $n$th approximants $f_{n}=b_{0}+\mathbf{K}_{i=1}^{n}\left(a_{i} / b_{i}\right)$ and $f_{n}^{*}=d_{0}+\mathbf{K}_{i=1}^{n}\left(c_{i} / d_{i}\right)$, respectively, are said to be equivalence if $f_{n}=f_{n}^{*}, n \in \mathbb{N}_{0}$. It is written as follows $b_{0}+\mathbf{K}\left(a_{i} / b i\right) \equiv d_{0}+\mathbf{K}\left(c_{i} / d_{i}\right)$.

Theorem 1. Continued fractions $b_{0}+\mathbf{K}\left(a_{i} / b_{i}\right)$ and $d_{0}+\mathbf{K}\left(c_{i} / d_{i}\right)$ are equivalent iff there exists a sequence of non-zero constants $\left\{r_{i}: r_{0}=1, r_{i} \neq 0, i \in \mathbb{N}\right\}$ such that

$$
d_{0}=b_{0}, c_{i}=r_{i-1} r_{i} a_{i}, d_{i}=r_{i} b_{i}, \quad i \in \mathbb{N} .
$$

Let the function of complex variable $g$ is defined on the compact set $\mathbf{Z} \subset \mathbb{C}$. Function $g$ can be interpolated on set of nodes $\mathcal{Z}=\left\{z_{i}: z_{i} \in \mathbf{Z}, z_{i} \neq z_{j}, i, j=\overline{0, n}\right\}$ by a Thiele interpolation continued fraction (T-ICF) of the form

$$
D_{n}(z ; g)=\frac{P_{n}(z ; g)}{Q_{n}(z ; g)}=b_{0}+\underset{k=1}{n}\left(\left(z-z_{k-1}\right) / b_{k}\left(z_{0}, z_{1}, \ldots, z_{k} ; g\right)\right)
$$

Canonical numerator $P_{n}(z ; g)$ and canonical denominator $Q_{n}(z ; g)$ of a T-ICF $(2.2)$ are polynomials whose degrees satisfy inequalities $\operatorname{deg} P_{n}(z ; g) \leq\left[\frac{n+1}{2}\right], \operatorname{deg} Q_{n}(z ; g) \leq\left[\frac{n}{2}\right]$.

By $\rho_{k}\left[z_{0}, z_{1}, \ldots, z_{k} ; g\right], k=\overline{0, n}$, denote the reciprocal difference of the $k$ th order. 
The reciprocal differences are calculated as follows

$$
\begin{aligned}
& \rho_{0}[z ; g]=g(z), \quad \rho_{1}\left[z_{0}, z ; g\right]=\frac{z-z_{0}}{\rho_{0}[z ; g]-\rho_{0}\left[z_{0} ; g\right]}, \\
& \rho_{2}\left[z_{0}, z_{1}, z ; g\right]=\rho_{0}\left[z_{0} ; g\right]+\frac{z-z_{1}}{\rho_{1}\left[z_{0}, z ; g\right]-\rho_{k-1}\left[z_{0}, z_{1} ; g\right]}, \\
& \rho_{k}\left[z_{0}, \ldots, z_{k-1}, z ; g\right]=\rho_{k-2}\left[z_{0}, \ldots, z_{k-2} ; g\right]+ \\
& \quad+\frac{z-z_{k-1}}{\rho_{k-1}\left[z_{0}, \ldots, z_{k-2}, z ; g\right]-\rho_{k-1}\left[z_{0}, \ldots, z_{k-2}, z_{k-1} ; g\right]}, \quad k=\overline{2, n} .
\end{aligned}
$$

Coefficients of a T-ICF (2.2) are determined by through reciprocal differences according to the formulae

$$
\begin{aligned}
& b_{0}\left(z_{0} ; g\right)=\rho_{0}\left[z_{0} ; g\right], b_{1}\left(z_{0}, z_{1} ; g\right)=\rho_{1}\left[z_{0}, z_{1} ; g\right], \\
& b_{2}\left(z_{0}, z_{1}, z_{2} ; g\right)=\rho_{2}\left[z_{0}, z_{1}, z_{2} ; g\right]-\rho_{0}\left[z_{0} ; g\right], \\
& b_{k}\left(z_{0}, \ldots, z_{k} ; g\right)=\rho_{k}\left[z_{0}, \ldots, z_{k} ; g\right]-\rho_{k-2}\left[z_{0}, \ldots, z_{k-2} ; g\right], \quad k=\overline{2, n} .
\end{aligned}
$$

It is known $[12,19]$ that the reciprocal difference of the $k$ th order $\rho_{k}\left[z_{0}, z_{1}, \ldots, z_{k} ; g\right]$ is determined by the relation of two determinants formed from interpolation nodes and function values in nodes. The reciprocal difference is the symmetric function of arguments $z_{0}, z_{1}, \ldots, z_{k}$.

Theorem 2. Let $D_{n}(z ; g)$ be a T-ICF of a function $g$ and $C=$ const. Then

$$
D_{n}(z ; C g)=C D_{n}(z ; g) .
$$

Proof. We first prove the auxiliary statement. The reciprocal differences of a function $C g$ satisfy the relation

$$
\rho_{k}\left[z_{0}, \ldots, z_{k} ; C g\right]= \begin{cases}C \rho_{k}\left[z_{0}, \ldots, z_{k} ; g\right], & k=2 m, \\ C^{-1} \rho_{k}\left[z_{0}, \ldots, z_{k} ; g\right], & k=2 m+1 .\end{cases}
$$

We shall prove the relation (2.6) by induction. When $k=0,1$ then the relation holds. Let's assume that formula (2.6) holds when $k=2 s-1,2 s$. For $k=2 s+1$ from (2.3) it follows

$$
\begin{aligned}
& \rho_{2 s+1}\left[z_{0}, \ldots, z_{2 s+1} ; C g\right]=\rho_{2 s-1}\left[z_{0}, \ldots, z_{2 s-1} ; C g\right]+ \\
& +\frac{z_{2 s+1}-z_{2 s}}{\rho_{2 s}\left[z_{0}, \ldots, z_{2 s-1}, z_{2 s+1} ; C g\right]-\rho_{2 s}\left[z_{0}, \ldots, z_{2 s-1}, z_{2 s} ; C g\right]}=\frac{1}{C} \rho_{2 s+1}\left[z_{0}, \ldots, z_{2 s+1} ; g\right] .
\end{aligned}
$$

Similarly, we get that $\rho_{2 s+2}\left[z_{0}, \ldots, z_{2 s+2} ; C g\right]=C \rho_{2 s+2}\left[z_{0}, \ldots, z_{2 s+2} ; g\right]$. The formula (2.6) is proved.

It follows from (2.4) and (2.6) that the coefficients of a T-ICF (2.2) of a function $C g$ satisfy the relation

$$
b_{k}\left(z_{0}, \ldots, z_{k} ; C g\right)= \begin{cases}C b_{k}\left(z_{0}, \ldots, z_{k} ; g\right), & k=2 m \\ C^{-1} b_{k}\left(z_{0}, \ldots, z_{k} ; g\right), & k=2 m+1 .\end{cases}
$$


Consider the a T-ICF of a function $C g$. We have

$$
D_{n}(z ; C g)=b_{0}\left(z_{0} ; C g\right)+\mathbb{K}_{k=1}^{n}\left(\left(z-z_{k-1}\right) / b_{n}\left(z_{0}, z_{1}, \ldots, z_{k} ; C g\right)\right) .
$$

We shall use the relation (2.7). Then we shall have that

$$
D_{n}(z ; C g)=C b_{0}\left(z_{0} ; g\right)+\stackrel{n}{K}_{k=1}\left(\left(z-z_{k-1}\right) /\left(C^{(-1)^{k}} b_{n}\left(z_{0}, z_{1}, \ldots, z_{k} ; g\right)\right)\right) .
$$

If we perform equivalent transformations (2.1) when $r_{k}=C^{(-1)^{k+1}}, k \in \mathbb{N}$ then we obtain (2.5).

Since the reciprocal difference of the $k$ th order $\rho_{k}\left[z_{0}, \ldots, z_{k} ; g\right], k=\overline{0, n}$, is a symmetric function of the arguments $z_{0}, z_{1}, \ldots, z_{k}$, then we can go to the limiting case.

Definition 3. If exist limit (finite number or infinity) of a reciprocal difference $k$ th order $\rho_{k}\left[z_{0}, \ldots, z_{k} ; g\right]$ when the nodes $z_{0}, \ldots, z_{k} \rightarrow z_{*}$, where $z_{*} \in \mathbf{Z}$ then the limit value is called the Thiele reciprocal derivative of a $k$ th order of a function $g$ at the point $z_{*}$ and is denoted ${ }^{(k)} g\left(z_{*}\right)$.

It follows from the definition that ${ }^{(k)} g\left(z_{*}\right)=\lim _{z_{0}, \ldots, z_{k} \rightarrow z_{*}} \rho_{k}\left[z_{0}, \ldots, z_{k} ; g\right]$. The Thiele reciprocal derivatives are calculated by the recurrent formula [11]

$$
{ }^{(1)} g\left(z_{*}\right)=\frac{1}{g^{\prime}\left(z_{*}\right)}, \quad{ }^{(k)} g\left(z_{*}\right)=\frac{k}{\left({ }^{(k-1)} g\left(z_{*}\right)\right)^{\prime}}+{ }^{(k-2)} g\left(z_{*}\right), \quad k=\overline{2, n} .
$$

Theorem 3 ([12]). If the function $g$ is analytic at $\mathbf{Z} \subset \mathbb{C}$ then Thiele reciprocal derivatives of a function $g$ at $z_{*} \in \mathbf{Z}$ are defined as follows

$$
{ }^{(2 k)} g\left(z_{*}\right)=\frac{H_{k+1}^{(0)}\left(z_{*}\right)}{H_{k}^{(2)}\left(z_{*}\right)}, \quad{ }^{(2 k-1)} g\left(z_{*}\right)=\frac{H_{k-1}^{(3)}\left(z_{*}\right)}{H_{k}^{(1)}\left(z_{*}\right)}, \quad k \in \mathbb{N},
$$

where Hankel determinants $H_{k}^{(m)}\left(z_{*}\right)$ are equals

$$
H_{0}^{(m)}\left(z_{*}\right)=1, H_{k}^{(m)}\left(z_{*}\right)=\left|\begin{array}{cccc}
c_{m} & c_{m+1} & \ldots & c_{m+k-1} \\
c_{m+1} & c_{m+2} & \ldots & c_{m+k} \\
\vdots & \vdots & \ddots & \vdots \\
c_{m+k-1} & c_{m+k} & \cdots & c_{m+2 k-2}
\end{array}\right| \neq 0, c_{s}=\frac{g^{(s)}\left(z_{*}\right)}{s !}, c_{s}=0, s<0
$$

Theorem 4 ([13]). (A) If determinants $H_{k+1}^{(0)}\left(z_{*}\right), H_{k}^{(2)}\left(z_{*}\right), H_{k-1}^{(3)}\left(z_{*}\right), H_{k}^{(1)}\left(z_{*}\right)$, where $k=\overline{0, n}$, be non-zero then a function $g$ at the point $z_{*}$ has finite Thiele reciprocal derivatives up to $(2 n)$ th order inclusive which may be calculated by formula (2.8) or by formula (2.9). 
(B) If $H_{n+1}^{(0)}\left(z_{*}\right) \neq 0$ and $H_{n}^{(2)}\left(z_{*}\right)=0$ then ${ }^{(2 n)} g\left(z_{*}\right)=0$. If $H_{n+1}^{(0)}\left(z_{*}\right)=0$ and $H_{n}^{(2)}\left(z_{*}\right) \neq 0$ then ${ }^{(2 n)} g\left(z_{*}\right)=\infty$.

(C) If $H_{n}^{(1)}\left(z_{*}\right) \neq 0$ and $H_{n+1}^{(-1)}\left(z_{*}\right)=0$ then ${ }^{(2 n-1)} g\left(z_{*}\right)=0$. If $H_{n}^{(1)}\left(z_{*}\right)=0$ and $H_{n+1}^{(-1)}\left(z_{*}\right) \neq 0$ then ${ }^{(2 n-1)} g\left(z_{*}\right)=\infty$.

Let the function $g$ have Thiele reciprocal derivatives at the point $z_{*} \in \mathbf{Z}$. Then we get the expansion of a function $g$ into a Thiele continued fraction $(\mathrm{T}-\mathrm{CF})$ in some neighbourhood of the point $z_{*}$, i.e.

$$
D(z ; g)=b_{0}\left(z_{*} ; g\right)+\underset{k=1}{\mathbf{K}}\left(\left(z-z_{*}\right) / b_{k}\left(z_{*} ; g\right)\right),
$$

where

$$
b_{0}\left(z_{*} ; g\right)=g\left(z_{*}\right), b_{1}\left(z_{*} ; g\right)={ }^{(1)} g\left(z_{*}\right), b_{k}\left(z_{*} ; g\right)={ }^{(k)} g\left(z_{*}\right)-{ }^{(k-2)} g\left(z_{*}\right), k \in \mathbb{N}_{2} .
$$

The Thiele reciprocal derivatives has properties that follows directly from properties of reciprocal differences. In particular

$$
{ }^{(2 n-1)}\left(C g\left(z_{*}\right)\right)=\frac{1}{C} \cdot{ }^{(2 n-1)} g\left(z_{*}\right),{ }^{(2 n)}\left(C g\left(z_{*}\right)\right)=C \cdot{ }^{(2 n)} g\left(z_{*}\right), C=\text { const }, n \in \mathbb{N} .
$$

From Theorem 2, definition of a Thiele reciprocal derivatives, formulae (2.11) and properties (2.12) it follows that

$$
D(z ; C g)=C D(z ; g), \quad C=\text { const. }
$$

Theorem 5 ([13]). Let the function $w=f(z)$ has a Thiele reciprocal derivative at the point $z_{0} \in G$ and let the function $u=g(w)$ has a Thiele reciprocal derivative at the point $w_{0} \in E$, where $w_{0}=f\left(z_{0}\right)$, then the composed function $F(z)=g(f(z))$ has a Thiele reciprocal derivative at point $z_{0}$ and ${ }^{(1)} F\left(z_{0}\right)={ }^{(1)} g\left(w_{0}\right) \cdot{ }^{(1)} f\left(z_{0}\right)$.

We shall prove the following property of Thiele reciprocal derivatives.

Theorem 6. Let the function $g$ has Thiele reciprocal derivatives and $C=$ const then

$$
{ }^{(2 k)}(g(C z))=\left.{ }^{(2 k)} g(v)\right|_{v=C z},{ }^{(2 k-1)}(g(C z))=\left.C^{-1} \cdot{ }^{(2 k-1)} g(v)\right|_{v=C z}, \quad k \in \mathbb{N} .
$$

Proof. From theorem 5 follows that ${ }^{(1)}(f(C z))=\left.\frac{1}{C} \cdot{ }^{(1)} f(v)\right|_{v=C z}$. It follows from here, from (2.8) and (2.12) that

$$
{ }^{(2)}(f(C z))=2 \cdot{ }^{(1)}\left({ }^{(1)}(f(C z))\right)+f(C z)=\left.\left(2 \cdot{ }^{(1)}\left(\frac{1}{C} \cdot{ }^{(1)} f(v)\right)+f(v)\right)\right|_{v=C z}=\left.{ }^{(2)} f(v)\right|_{v=C z} .
$$

Suppose that the formulas (2.14) are true when $k=\overline{1, s-1}$. Then when $k=s$ from (2.12) we have that

$$
\begin{aligned}
{ }^{(2 s)}(f(C z))=2 s \cdot{ }^{(1)} & \left({ }^{(2 s-1)}(f(C z))\right)+{ }^{(2 s-2)}(f(C z))= \\
& =\left.2 s \cdot\left({ }^{(1)}\left(\frac{1}{C} \cdot{ }^{(2 s-1)} f(v)\right)+{ }^{(2 s-2)} f(v)\right)\right|_{v=C z}=\left.{ }^{(2 s)} f(v)\right|_{v=C z} .
\end{aligned}
$$


The relation

$$
\left({ }^{(2 s+1)}(f(C z))=\left.(2 s+1) \cdot\left({ }^{(1)}\left({ }^{(2 s)}(f(v))\right)^{(2 s-1)}(f(v))\right)\right|_{v=C z}=\left.\frac{1}{C} \cdot{ }^{(2 s+1)} f(v)\right|_{v=C z} .\right.
$$

is similarly proved.

It follows from the Theorem 6 that

$$
b_{2 n}\left(C z_{*} ; g\right)=\left.b_{2 n}(v ; g)\right|_{v=C z_{*}}, \quad b_{2 n+1}\left(C z_{*} ; g\right)=\left.\frac{1}{C} \cdot b_{2 n+1}(v ; g)\right|_{v=C z_{*}}, n \in \mathbb{N}_{0} .
$$

A T-CF (2.10) can be given by an equivalent continued fraction with partial denominators equal to one. We have

$$
F(z ; g)=a_{0}\left(z_{*} ; g\right)+\underset{n=1}{\mathbf{K}}\left(a_{n}\left(z_{*} ; g\right)\left(z-z_{*}\right) / 1\right) .
$$

The coefficients of a continued fraction (2.17) can be determined by the coefficients of a T-CF as follows

$$
a_{0}\left(z_{*} ; g\right)=b_{0}\left(z_{*} ; g\right), a_{1}\left(z_{*}\right)=\frac{1}{b_{1}\left(z_{*} ; g\right)}, a_{n}\left(z_{*} ; g\right)=\frac{1}{b_{n-1}\left(z_{*} ; g\right) b_{n}\left(z_{*} ; g\right)}, n \in \mathbb{N}_{2}
$$

Let the function $g$ is expanded in a formal power series at the neighbourhood of a point $z_{*}$. It is proved in [13] that (2.17) is equal to a regular continued $\mathrm{C}$-fraction $(\mathrm{C}-\mathrm{CF})$. Since the a $\mathrm{C}-\mathrm{CF}$ is corresponding to the formal power series, then a $\mathrm{T}-\mathrm{CF}$ will also correspond to the formal power series. It's easy to make sure that $F(z ; C g)=$ $C F(z ; g), C=$ const.

Theorem 7 ([13]). Let the function $g$ be expanded into a $C-C F$ (2.17) in the some neighbourhood of a point $z_{*} \in \mathbf{Z}$ and $\lim _{n \rightarrow \infty} a_{n}\left(z_{*} ; g\right)=a, a \in \mathbb{C}, a \neq 0$.

(A) The continued fraction (2.17) converge to the function $g$ which is meromorphic in the domain $\mathbf{R}_{a}=\left\{z \in \mathbb{C}:\left|\arg \left(a\left(z-z_{*}\right)+1 / 4\right)\right|<\pi\right\}$.

(B) The convergence will be uniform on an arbitrary compact set $\mathbf{C} \subset \mathbf{R}_{a}$ which not contains poles of a function $g$.

(C) The function $g$ is holomorphic at the point $z_{*}$.

Theorem 8 ([13]). Let the function $g$ be expanded into a $C-C F(2.17)$ in the some neighbourhood of the point $z_{*} \in \mathbf{Z}, a_{n}\left(z_{*} ; g\right) \neq 0$ and $\lim _{n \rightarrow \infty} a_{n}\left(z_{*} ; g\right)=0$.

(A) The continued fraction (2.17) converge to the function $g$.

(B) The convergence will be uniform on an arbitrary compact set $\mathbf{Z} \subset \mathbb{C}$ which not contains poles of a function $g$.

(C) The function $g$ is holomorphic at the point $z_{*}$ and $g\left(z_{*}\right)=a_{0}\left(z_{*} ; g\right)$. 


\section{Representation of functions of two variables by bicontinued fractions}

The results obtained in the previous section, allow us to specify a way of representation functions of two complex variables of the form

$$
u(z, w)=f(z) h(w)
$$

by the product of two continued fractions for each variable. We shall call this product a bicontinued fraction.

Let the function $u$ be defined on the compact set $\mathbf{K}=\mathbf{Z} \times \mathbf{W} \subset \mathbb{C}^{2}$. Suppose that functions $f$ and $h$ are analytic on the compact sets $\mathbf{Z}$ and $\mathbf{W}$ respectively. Then, according to Theorem 3 and Theorem 4, each of these functions has Thiele reciprocal derivatives.

Let $\bar{w} \in \mathbf{W}$ be a fixed point and $H=h(\bar{w})$. The auxiliary function $\mathcal{F}(z)=H f(z)$ can be expanded into a $\mathrm{T}-\mathrm{CF}$ about variable $z$ on the compact set $\mathbf{Z}$. If considers properties of the Thiele continued fraction (2.13) than we obtain the expansion of a function $\mathcal{F}$ in a neighbourhood of the point $z_{*} \in \mathbf{Z}$ into a $\mathrm{T}-\mathrm{CF}$ about variable $z$

$$
D(z ; f)=H\left(b_{0}\left(z_{*} ; f\right)+\mathbb{K}_{n=1}^{\infty}\left(\left(z-z_{*}\right) / b_{n}\left(z_{*} ; f\right)\right)\right) .
$$

Similarly, let $\bar{z} \in \mathbf{Z}$ be a fixed point and $F=f(\bar{z})$, then the auxiliary function $\mathcal{H}(w)=F h(w)$ can be expanded into a $\mathrm{T}-\mathrm{CF}$ in the neighbourhood of the point $w_{*} \in \mathbf{W}$ about variable $w$

$$
D(z ; h)=F\left(b_{0}\left(w_{*} ; h\right)+\underset{n=1}{\mathbf{K}}\left(\left(w-w_{*}\right) / b_{n}\left(w_{*} ; h\right)\right)\right) .
$$

Since the point $(\bar{z}, \bar{w})$ is an arbitrary point of the compact set $\mathbf{K}$ then we get a representation of a function $u$ as the product of two $\mathrm{T}-\mathrm{CF}$ in the neighbourhood of a point $\left(z_{*}, w_{*}\right) \in \mathbf{K}$

$$
\begin{aligned}
\left.\mathbf{B}(z, w ; f h)=\left(b_{0}\left(z_{*} ; f\right)+\stackrel{\mathbf{K}}{n=1}_{(}^{\infty}\left(z-z_{*}\right) / b_{n}\left(z_{*} ; f\right)\right)\right) \times & \\
\left(b_{0}\left(w_{*} ; h\right)\right. & \left.\left.+\stackrel{\mathbf{K}}{n=1}_{(}^{\infty}\left(w-w_{*}\right) / b_{n}\left(w_{*} ; h\right)\right)\right) .
\end{aligned}
$$

We call this product a Thiele bicontinued fraction (T-BCF). Similarly, the function $u$ can be represented by a bicontinued $\mathrm{C}$-fraction $(\mathrm{C}-\mathrm{BCF})$

$$
\begin{aligned}
\mathbf{C}(z, w ; f h)=\left(a_{0}\left(z_{*} ; f\right)+\stackrel{\mathbf{K}}{n=1}_{\left.\left(a_{n}\left(z_{*} ; f\right)\left(z-z_{*}\right) / 1\right)\right) \times}\right. \\
\left(a_{0}\left(w_{*} ; h\right)+\mathbf{K}_{n=1}^{\infty}\left(a_{n}\left(w_{*} ; h\right)\left(w-w_{*}\right) / 1\right)\right) .
\end{aligned}
$$

We shall consider examples of function representations by bicontinued fractions and we shall show the domains of convergence and domains of uniform convergence of such representations too. 
Example 1. Consider the function $u_{1}(z, w)=(\delta+\beta z)^{\alpha} \operatorname{tg}(\varepsilon+\gamma w)$, where $\alpha \in \mathbb{C} \backslash\{\mathbb{Z}\}$, $\beta, \gamma, \delta, \varepsilon \in \mathbb{C} \backslash\{0\}$.

Theorem 9. (A) The function $u_{1}(z, w)=(\delta+\beta z)^{\alpha} \operatorname{tg}(\varepsilon+\gamma w)$ can be represented: 1) by a $T-B C F$

$$
\begin{gathered}
\mathbf{B}\left(z, w ; u_{1}\right)=\xi^{\alpha}\left(1+\frac{\alpha \beta\left(z-z_{*}\right)}{\xi}+\frac{(1-\alpha) \beta\left(z-z_{*}\right)}{2}+\frac{(\alpha+1) \beta\left(z-z_{*}\right)}{3 \xi}+\cdots+\right. \\
\left.+\frac{(n-\alpha) \beta\left(z-z_{*}\right)}{2}+\frac{(n+\alpha) \beta\left(z-z_{*}\right)}{(2 n+1) \xi}+\ldots\right)\left(\psi+\frac{\gamma\left(1+\psi \psi^{2}\right)\left(w-w_{*}\right)}{1}+\right. \\
+\frac{\gamma \psi\left(w-w_{*}\right)}{-1}+\frac{\gamma\left(w-w_{*}\right)}{3 \psi}+\frac{\gamma\left(w-w_{*}\right)}{1}+\ldots+\frac{\gamma \psi\left(w-w_{*}\right)}{4 n+1}+\frac{\gamma \psi\left(w-w_{*}\right)}{-1}+ \\
\left.+\frac{\gamma\left(w-w_{*}\right)}{(4 n+3) \psi}+\frac{\gamma\left(w-w_{*}\right)}{1}+\ldots\right), \quad \xi=\delta+\beta z_{*}, \psi=\operatorname{tg}\left(\varepsilon+\gamma w_{*}\right) ;
\end{gathered}
$$

2) by a $C-B C F$

$$
\begin{array}{r}
\mathbf{C}\left(z, w ; u_{1}\right)=\xi^{\alpha}\left(1+\frac{\frac{\alpha \beta}{\xi}\left(z-z_{*}\right)}{1}+\frac{\frac{(1-\alpha) \beta}{2 \xi}\left(z-z_{*}\right)}{1}+\frac{\frac{(\alpha+1) \beta}{6 \xi}\left(z-z_{*}\right)}{1}+\cdots+\right. \\
\left.+\frac{\frac{(n-\alpha) \beta}{(4 n-2) \xi}\left(z-z_{*}\right)}{1}+\frac{\frac{(n+\alpha) \beta}{(4 n+2) \xi}\left(z-z_{*}\right)}{1}+\ldots\right)\left(\psi+\frac{\gamma\left(1+\psi^{2}\right)\left(w-w_{*}\right)}{1}+\right. \\
+\frac{-\gamma \psi\left(w-w_{*}\right)}{1}+\frac{-\frac{\gamma}{3 \psi}\left(w-w_{*}\right)}{1}+\frac{\frac{\gamma}{3 \psi}\left(w-w_{*}\right)}{1}+\ldots+\frac{\frac{\gamma \psi}{4 n+1}\left(w-w_{*}\right)}{1}+ \\
\left.+\frac{\frac{-\gamma \psi}{4 n+1}\left(w-w_{*}\right)}{1}+\frac{\frac{-\gamma}{(4 n+3) \psi}\left(w-w_{*}\right)}{1}+\frac{\frac{\gamma}{(4 n+3) \psi}\left(w-w_{*}\right)}{1}+\ldots\right)
\end{array}
$$

in the some neighbourhood of a point $\left(z_{*}, w_{*}\right) \in \mathbb{C} \times \mathbf{G}(\varepsilon, \gamma ; w)$, where $\mathbf{G}(\varepsilon, \gamma ; w)=$ $\mathbb{C} \backslash\left\{\gamma w \neq \frac{k \pi}{2}-\varepsilon, k \in \mathbb{Z}\right\}$,

(B) The $T-B C F$ (3.4) and the $C-B C F$ (3.5) converge to a function $u_{1}(z, w)$ on a domain $\mathbf{R}\left(\delta, \beta, z_{*} ; z\right) \times \mathbf{G}(\varepsilon, \gamma ; w), \mathbf{R}\left(\delta, \beta, z_{*} ; z\right)=\left\{z \in \mathbb{C}:\left|\arg (\delta+\beta z)-\arg \left(\delta+\beta z_{*}\right)\right|<\right.$ $\pi\}$.

(C) Bicontinued fractions converge uniformly on a arbitrary compact set $\mathbf{K} \subset$ $\mathbf{R}\left(\delta, \beta, z_{*} ; z\right) \times \mathbf{G}(\varepsilon, \gamma ; w)$.

Proof. It is proved in [13] that the coefficients of expansion function $(\delta+z)^{\alpha}$ into a $\mathrm{T}-\mathrm{CF}$ in the neighbourhood of a point $z_{*} \in \mathbb{C} \backslash\{-\delta\}$ are equals

$$
\begin{aligned}
b_{1}\left(z_{*} ;(\delta+z)^{\alpha}\right) & =\frac{\delta+z_{*}}{\alpha\left(\delta+z_{*}\right)^{\alpha}}, b_{2 n}\left(z_{*} ;(\delta+z)^{\alpha}\right)=\frac{2 \prod_{i=0}^{n-1}(\alpha+i)\left(\delta+z_{*}\right)^{\alpha}}{\prod_{i=1}^{n}(i-\alpha)}, \\
b_{2 n+1}\left(z_{*} ;(\delta+z)^{\alpha}\right) & =\frac{(2 n+1) \prod_{i=1}^{n}(i-\alpha)}{\prod_{i=0}^{n}(\alpha+i)\left(\delta+z_{*}\right)^{\alpha-1}}, \quad n \in \mathbb{N} .
\end{aligned}
$$


From (2.16) and (3.6) it follows that the coefficients of expansion of a function $(\delta+\beta z)^{\alpha}$ into a $\mathrm{T}-\mathrm{CF}$ in the neighbourhood of a point $z_{*} \in \mathbb{C} \backslash\{-\delta / \beta\}$ will be equals

$$
\begin{aligned}
b_{1}\left(z_{*} ;(\delta+\beta z)^{\alpha}\right) & =\frac{1}{\alpha \beta\left(\delta+\beta z_{*}\right)^{\alpha-1}}, b_{2 n}\left(z_{*} ;(\delta+\beta z)^{\alpha}\right)=\frac{2 \prod_{i=0}^{n-1}(\alpha+i)\left(\delta+\beta z_{*}\right)^{\alpha}}{\prod_{i=1}^{n}(i-\alpha)}, \\
b_{2 n+1}\left(z_{*},(\delta+\beta z)^{\alpha}\right) & =\frac{(2 n+1) \prod_{i=1}^{n}(i-\alpha)}{\beta \prod_{i=0}^{n}(\alpha+i)\left(\delta+\beta z_{*}\right)^{\alpha-1}}, \quad n \in \mathbb{N} .
\end{aligned}
$$

We make the notation $\xi=\delta+\beta z_{*}$. Let the sequence $\left\{r_{i}\right\}$ be defined as follows

$$
r_{0}=1, r_{1}=\alpha \beta \xi^{\alpha}, r_{2}=\frac{1-\alpha}{\alpha \xi^{\alpha}}, r_{2 n}=\frac{\prod_{i=1}^{n}(i-\alpha)}{\xi^{\alpha} \prod_{i=0}^{n-1}(\alpha+i)}, r_{2 n+1}=\frac{\xi^{\alpha} \beta \prod_{i=0}^{n}(\alpha+i)}{\prod_{i=1}^{n}(i-\alpha)} .
$$

We shall be performed equivalent transforms (2.1) using the sequence $\left\{r_{i}\right\}$. We shall obtain the expansion of a function $(\delta+\beta z)^{\alpha}$ in the neighbourhood of a point $z_{*} \in$ $\mathbb{C} \backslash\{-\delta / \beta\}$ into a $\mathrm{T}-\mathrm{CF}$

$$
\begin{aligned}
D\left(z ;(\delta+\beta z)^{\alpha}\right) & =\xi^{\alpha}\left(1+\frac{\alpha \beta\left(z-z_{*}\right)}{\xi}+\frac{(1-\alpha) \beta\left(z-z_{*}\right)}{2}+\frac{(\alpha+1) \beta\left(z-z_{*}\right)}{3 \xi}+\right. \\
& \left.+\cdots+\frac{(n-\alpha) \beta\left(z-z_{*}\right)}{2}+\frac{(n+\alpha) \beta\left(z-z_{*}\right)}{(2 n+1) \xi}+\ldots\right), \quad \xi=\delta+\beta z_{*}
\end{aligned}
$$

We can rewrite a $\mathrm{T}-\mathrm{CF}$ (3.7) in the form of a equivalent $\mathrm{C}-\mathrm{CF}$. From (2.18) we get

$$
\begin{array}{r}
F\left(z ;(\delta+\beta z)^{\alpha}\right)=\xi^{\alpha}(1+ \\
+\frac{\frac{\alpha \beta}{\xi}\left(z-z_{*}\right)}{1}+\frac{\frac{(1-\alpha) \beta}{2 \xi}\left(z-z_{*}\right)}{1}+\frac{\frac{(\alpha+1) \beta}{6 \xi}\left(z-z_{*}\right)}{1}+ \\
+\cdots+\frac{\left.\frac{\frac{(n-\alpha) \beta}{(4 n-2) \xi}\left(z-z_{*}\right)}{1}+\frac{\frac{(n+\alpha) \beta}{(4 n+2) \xi}\left(z-z_{*}\right)}{1}+\ldots\right) .}{}+
\end{array}
$$

Since

$$
\lim _{n \rightarrow \infty} \frac{(n-\alpha) \beta}{(4 n-2)\left(\delta+\beta z_{*}\right)}=\lim _{n \rightarrow \infty} \frac{(n+\alpha) \beta}{(4 n+2)\left(\delta+\beta z_{*}\right)}=\frac{\beta}{4\left(\delta+\beta z_{*}\right)}
$$

and

$$
\arg \left(\frac{\left(z-z_{*}\right) \beta}{4\left(\delta+\beta z_{*}\right)}+\frac{1}{4}\right)=\arg \left(\frac{\delta+\beta z}{4\left(\delta+\beta z_{*}\right)}\right)=\arg (\delta+\beta z)-\arg \left(\delta+\beta z_{*}\right)
$$

then by Theorem 7 we obtain that the continued fractions (3.7) and (3.8) will be converge to the function $(\delta+\beta z)^{\alpha}$ on the domain $\mathbf{R}\left(\delta, \beta, z_{*} ; z\right)$ and on an arbitrary compact set $\mathbf{Z} \subset \mathbf{R}\left(\delta, \beta, z_{*} ; z\right)$ the continued fractions will be converge uniformly.

It is known $([11,13])$ that the coefficients of the expansion of a function $\operatorname{tg} w$ into a $\mathrm{T}-\mathrm{CF}$ in the neighbourhood of a point $w_{*} \in \mathbb{C} \backslash\left\{\frac{k \pi}{2}, k \in \mathbb{Z}\right\}$ are equals

$$
\begin{aligned}
& b_{4 n+1}\left(w_{*} ; \operatorname{tg} w\right)=\frac{4 n+1}{1+\operatorname{tg}^{2} w_{*}}, \quad b_{4 n+2}\left(z_{*} ; \operatorname{tg} w\right)=-\frac{1+\operatorname{tg}^{2} w_{*}}{\operatorname{tg} w_{*}}, \\
& b_{4 n+3}\left(w_{*} ; \operatorname{tg} w\right)=\frac{(4 n+3) \operatorname{tg}^{2} w_{*}}{1+\operatorname{tg}^{2} w_{*}}, \quad b_{4 n+4}\left(w_{*} ; \operatorname{tg} w\right)=\frac{1+\operatorname{tg}^{2} w_{*}}{\operatorname{tg} w_{*}}, \quad n \in \mathbb{N}_{0} .
\end{aligned}
$$


It follows from (2.16) and (3.9) that coefficients of expansion of a function $\operatorname{tg}(\varepsilon+\gamma w)$ into a $\mathrm{T}-\mathrm{CF}$ in the neighbourhood of a point $w_{*} \in W=\mathbb{C} \backslash\left\{\left(\frac{k p i}{2}-\varepsilon\right) / \gamma, k \in \mathbb{Z}\right\}$ will be equals

$$
\begin{aligned}
& b_{4 n+1}\left(w_{*} ; \operatorname{tg}(\varepsilon+\gamma w)\right)=\frac{4 n+1}{\gamma\left(1+\psi^{2}\right)}, b_{4 n+2}\left(w_{*} ; \operatorname{tg}(\varepsilon+\gamma w)\right)=-\frac{1+\psi^{2}}{\psi} \\
& b_{4 n+3}\left(w_{*} ; \operatorname{tg}(\varepsilon+\gamma w)\right)=\frac{(4 n+3) \psi^{2}}{\gamma\left(1+\psi^{2}\right)}, b_{4 n+4}\left(w_{*} ; \operatorname{tg}(\varepsilon+\gamma w)\right)=\frac{1+\psi^{2}}{\psi}
\end{aligned}
$$

were $\psi=\operatorname{tg}\left(\varepsilon+\gamma w_{*}\right), n \in \mathbb{N}_{0}$. We define the elements of the sequence $\left\{r_{i}\right\}$ as follows

$$
r_{4 n+1}=\gamma\left(1+\psi^{2}\right), r_{4 n+2}=\frac{\psi}{1+\psi^{2}}, r_{4 n+3}=\frac{\gamma\left(1+\psi^{2}\right)}{\psi}, r_{4 n+4}=\frac{\psi}{1+\psi^{2}}, n \in \mathbb{N}_{0} .
$$

After equivalent transforms (2.1) we obtain the expansion of a function $\operatorname{tg}(\varepsilon+\gamma w)$ into a $\mathrm{T}-\mathrm{CF}$

$$
\begin{gathered}
D(w ; \operatorname{tg}(\varepsilon+\gamma w))=\psi+\frac{\gamma\left(1+\psi^{2}\right)\left(w-w_{*}\right)}{1}+\frac{\gamma \psi\left(w-w_{*}\right)}{-1}+ \\
+\begin{array}{r}
\frac{\gamma\left(w-w_{*}\right)}{3 \psi}+\frac{\gamma\left(w-w_{*}\right)}{1}+\cdots+\frac{\gamma \psi\left(w-w_{*}\right)}{4 n+1}+ \\
+\frac{\gamma \psi\left(w-w_{*}\right)}{-1}+\frac{\gamma\left(w-w_{*}\right)}{(4 n+3) \psi}+\frac{\gamma\left(w-w_{*}\right)}{1}+\cdots
\end{array}
\end{gathered}
$$

We find the coefficients of a C-CF using the formulas (2.18). We have expansion

$$
\begin{aligned}
\operatorname{tg}(\varepsilon+\gamma w) & \psi+\frac{\gamma\left(1+\psi^{2}\right)\left(w-w_{*}\right)}{1}+\frac{-\gamma \psi\left(w-w_{*}\right)}{1}+\frac{-\frac{\gamma}{3 \psi}\left(w-w_{*}\right)}{1}+ \\
+ & +\cdots+\frac{\frac{\frac{\gamma}{3 \psi}\left(w-w_{*}\right)}{1}+\cdots}{1}+\frac{\frac{\gamma \psi}{4 n+1}\left(w-w_{*}\right)}{1}+\frac{\frac{-\gamma \psi}{4 n+1}\left(w-w_{*}\right)}{1}+ \\
& +\frac{\frac{-\gamma}{(4 n+3) \psi}\left(w-w_{*}\right)}{1}+\frac{\frac{\gamma}{(4 n+3) \psi}\left(w-w_{*}\right)}{1}+\cdots
\end{aligned}
$$

Since

$$
\frac{\gamma \psi}{4 n+1} \neq 0, \quad \frac{\gamma}{(4 n+3) \psi} \neq 0, \quad \lim _{n \rightarrow \infty} \frac{\gamma \psi}{4 n+1}=\lim _{n \rightarrow \infty} \frac{\gamma}{(4 n+3) \psi}=0, \quad w_{*} \in W
$$

then from Theorem 8 follows that a $\mathrm{T}-\mathrm{CF}$ (3.10) and a $\mathrm{C}-\mathrm{CF}$ (3.11) converge to the function $\operatorname{tg}(\varepsilon+\gamma w)$ in the domain $\mathbf{G}(\varepsilon, \gamma ; w)$ and on an arbitrary compact set $\mathbf{W} \subset \mathbf{G}(\varepsilon, \gamma ; w)$ continued fractions converge uniformly.

The function $u_{1}$ has the form (3.1), then this theorem follows from (3.2) and (3.3).

Remark 1. Let $\alpha$ be integer number, i.e. $\alpha \in \mathbb{Z}$, then a function $(\delta+z)^{\alpha}$ will be represented by a finite $\mathrm{T}-\mathrm{CF}([13])$. 
Example 2. Consider the function $u_{2}(z, w)=e^{\alpha z} \ln (\beta+\gamma w)$, where $\alpha, \beta, \gamma \in \mathbb{C} \backslash\{0\}$.

Theorem 10. Let's have a domain

$$
\mathbf{L}\left(\beta, \gamma, w_{*} ; w\right)=\left\{w: w \in \mathbb{C} \backslash\{-\beta / \gamma\},\left|\arg (\beta+\gamma w)-\arg \left(\beta+\gamma w_{*}\right)\right|<\pi\right\} .
$$

(A) A function $u_{2}(z, w)=e^{\alpha z} \ln (\beta+\gamma w)$ can be represented:

1) by a $T-B C F$

$$
\begin{aligned}
& \mathbf{B}\left(z, w ; u_{2}\right)=e^{\alpha z_{*}}\left(1+\frac{\alpha\left(z-z_{*}\right)}{1}+\frac{\alpha\left(z-z_{*}\right)}{-2}+\frac{\alpha\left(z-z_{*}\right)}{-3}+\frac{\alpha\left(z-z_{*}\right)}{2}+\right. \\
& \left.+\cdots+\frac{\alpha\left(z-z_{*}\right)}{(-1)^{n-1}(2 n-1)}+\frac{\alpha\left(z-z_{*}\right)}{(-1)^{n} 2}+\ldots\right)\left(\ln \tau+\frac{\gamma\left(w-w_{*}\right)}{\tau}+\right. \\
& +\frac{\gamma\left(w-w_{*}\right)}{2}+\frac{\gamma\left(w-w_{*}\right)}{3 \tau}+\frac{2 \gamma\left(w-w_{*}\right)}{2}+\frac{2 \gamma\left(w-w_{*}\right)}{5 \tau}+ \\
& \left.+\cdots+\frac{n \gamma\left(w-w_{*}\right)}{2}+\frac{n \gamma\left(w-w_{*}\right)}{(2 n+1) \tau}+\ldots\right), \quad \tau=\beta+\gamma w_{*} .
\end{aligned}
$$

2) by a $C-B C F$

$$
\begin{aligned}
& \mathbf{C}\left(z, w ; u_{2}\right)=e^{\alpha z_{*}}\left(1+\frac{\alpha\left(z-z_{*}\right)}{1}+\frac{\frac{-\alpha}{2}\left(z-z_{*}\right)}{1}+\frac{\frac{\alpha}{6}\left(z-z_{*}\right)}{1}+\frac{\frac{-\alpha}{6}\left(z-z_{*}\right)}{1}+\right. \\
& \left.+\frac{\frac{\alpha}{10}\left(z-z_{*}\right)}{1}+\cdots+\frac{\frac{-\alpha}{2(2 n-1)}\left(z-z_{*}\right)}{1}+\frac{\frac{\alpha}{2(2 n+1)}\left(z-z_{*}\right)}{1}+\ldots\right) \times \\
& \left(\ln \tau+\frac{\frac{\gamma}{\tau}\left(w-w_{*}\right)}{1}++\frac{\frac{\gamma}{2 \tau}\left(w-w_{*}\right)}{1}+\frac{\frac{\gamma}{6 \tau}\left(w-w_{*}\right)}{1}+\right. \\
& \left.+\cdots+\frac{\frac{n \gamma}{2(2 n-1) \tau}\left(w-w_{*}\right)}{1}+\frac{\frac{n \gamma}{2(2 n+1) \tau}\left(w-w_{*}\right)}{1}+\ldots\right) \text {. }
\end{aligned}
$$

in the neighbourhood of a point $\left(z_{*}, w_{*}\right) \in \mathbb{C} \times \mathbf{L}\left(\beta, \gamma, w_{*} ; w\right)$.

(B) Bicontinued fractions (3.12) and (3.13) converge to the function $u_{2}$ in the domain $\mathbb{C} \times \mathbf{L}\left(\beta, \gamma, w_{*} ; w\right)$.

(C) Bicontinued fractions (3.12) and (3.13) converge uniformly on the on an arbitrary compact set $\mathbf{K} \subset \mathbb{C} \times \mathbf{L}\left(\beta, \gamma, w_{*} ; w\right)$.

Proof. It is well-known $([18,19])$ that the coefficients of the expansion of a function $e^{z}$ in the neighbourhood of a point $z_{*} \in \mathbb{C}$ into a $\mathrm{T}-\mathrm{CF}$ are equals

$$
b_{2 n-1}\left(z_{*} ; e^{z}\right)=(-1)^{n+1}(2 n-1) e^{-z_{*}}, b_{2 n}\left(z_{*} ; e^{z}\right)=(-1)^{n} 2 e^{z_{*}}, \quad n \in \mathbb{N} .
$$

It follows from (2.16) and (3.14) that the coefficients of the expansion of a function $e^{\alpha z}$ into a $\mathrm{T}-\mathrm{CF}$ in the neighbourhood of a point $z_{*} \in \mathbb{C}$ will be equals

$$
b_{2 n-1}\left(z_{*} ; e^{\alpha z}\right)=\frac{(-1)^{n+1}}{\alpha}(2 n-1) e^{-\alpha z_{*}}, \quad b_{2 n}\left(z_{*} ; e^{\alpha z}\right)=(-1)^{n} 2 e^{\alpha z_{*}}, \quad n \in \mathbb{N} .
$$


If the sequence $\left\{r_{i}\right\}$ is defined as follows $r_{2 n-1}=\alpha e^{\alpha z_{*}}, r_{2 n}=e^{-\alpha z_{*}}, n \in \mathbb{N}$, then after equivalent transformations we obtain the expansion of a function $e^{\alpha z}$ into a $\mathrm{T}-\mathrm{CF}$

$$
\begin{gathered}
D\left(z ; e^{\alpha z}\right)=e^{\alpha z_{*}}\left(1+\frac{\alpha\left(z-z_{*}\right)}{1}+\frac{\alpha\left(z-z_{*}\right)}{-2}+\frac{\alpha\left(z-z_{*}\right)}{-3}+\frac{\alpha\left(z-z_{*}\right)}{2}+\frac{\alpha\left(z-z_{*}\right)}{5}+\right. \\
\left.+\frac{\alpha\left(z-z_{*}\right)}{-2}+\frac{\alpha\left(z-z_{*}\right)}{-7}+\cdots+\frac{\alpha\left(z-z_{*}\right)}{(-1)^{n-1}(2 n-1)}+\frac{\alpha\left(z-z_{*}\right)}{(-1)^{n} 2}+\ldots\right) \cdot
\end{gathered}
$$

The expansion of a function into a $\mathrm{C}-\mathrm{CF}$ will be written as follow

$$
\begin{aligned}
F\left(z ; e^{\alpha z}\right)=e^{\alpha z_{*}} & \left(1+\frac{\alpha\left(z-z_{*}\right)}{1}+\frac{\frac{-\alpha}{2}\left(z-z_{*}\right)}{1}+\frac{\frac{\alpha}{6}\left(z-z_{*}\right)}{1}+\frac{\frac{-\alpha}{6}\left(z-z_{*}\right)}{1}+\right. \\
+ & \left.\frac{\frac{\alpha}{10}\left(z-z_{*}\right)}{1}+\cdots+\frac{\frac{-\alpha}{2(2 n-1)}\left(z-z_{*}\right)}{1}+\frac{\frac{\alpha}{2(2 n+1)}\left(z-z_{*}\right)}{1}+\ldots\right)
\end{aligned}
$$

Since

$$
a_{2 n-1}\left(z_{*} ; f\right)=\frac{-\alpha}{2(2 n-1)} \neq 0, \quad a_{2 n}\left(z_{*} ; f\right)=\frac{\alpha}{2(2 n+1)} \neq 0
$$

and in addition

$$
\lim _{n \rightarrow \infty} \frac{-\alpha}{2(2 n-1)}=\lim _{n \rightarrow \infty} \frac{\alpha}{2(2 n+1)}=0,
$$

it follows from Theorem 8 that continued fractions (3.15) and (3.16) converge to the function $e^{\alpha z}$ on complex plane $\mathbb{C}$ and on an arbitrary compact set $\mathbf{Z} \subset \mathbb{C}$ continued fractions converge uniformly.

In the monograph [13] was proved that the coefficients of the expansion of a function $\ln (\beta+w)$ into a $\mathrm{T}-\mathrm{CF}$ in the neighbourhood of a point $w_{*} \in \mathbb{C} \backslash\{-\beta\}$ takes values

$$
b_{2 n-1}\left(w_{*} ; \ln (\beta+w)\right)=(2 n-1)\left(\beta+w_{*}\right), \quad b_{2 n}\left(w_{*} ; \ln (\beta+w)\right)=\frac{2}{n}, \quad n \in \mathbb{N} .
$$

Similar to the previous case, it follows from (2.16) and (3.17) that the coefficients of the expansion of a function $\ln (\beta+\gamma w)$ into a $\mathrm{T}-\mathrm{CF}$ in the neighbourhood of a point $w_{*} \in W=\mathbb{C} \backslash\{-\beta / \delta\}$ are defined by formulae

$$
b_{2 n-1}\left(w_{*} ; \ln (\beta+\gamma w)\right)=\frac{2 n+1}{\gamma}\left(\beta+\gamma w_{*}\right), \quad b_{2 n}\left(w_{*} ; \ln (\beta+\gamma w)\right)=\frac{2}{n}, \quad n \in \mathbb{N} .
$$

Let the elements of the sequence $\left\{r_{i}\right\}$ be equals $r_{2 n-1}=\gamma, r_{2 n}=n, n \in \mathbb{N}$. After the equivalent transforms (2.1) we get the extension of a function into a $\mathrm{T}-\mathrm{CF}$, i.e.

$$
\begin{aligned}
& D(w ; \ln (\beta+\gamma w))=\ln \tau+\frac{\gamma\left(w-w_{*}\right)}{\tau}+\frac{\gamma\left(w-w_{*}\right)}{2}+\frac{\gamma\left(w-w_{*}\right)}{3 \tau}+\frac{2 \gamma\left(w-w_{*}\right)}{2}+ \\
& +\frac{2 \gamma\left(w-w_{*}\right)}{5 \tau}+\cdots+\frac{n \gamma\left(w-w_{*}\right)}{2}+\frac{n \gamma\left(w-w_{*}\right)}{(2 n+1) \tau}+\ldots, \quad \tau=\beta+\gamma w_{*} .
\end{aligned}
$$


In accordance by (2.18) the extension of a function into a $\mathrm{C}-\mathrm{CF}$ will be written as

$$
\begin{gathered}
F(w ; \ln (\beta+\gamma w))=\ln \tau+\frac{\frac{\gamma}{\tau}\left(w-w_{*}\right)}{1}+\frac{\frac{\gamma}{2 \tau}\left(w-w_{*}\right)}{1}+\frac{\frac{\gamma}{6 \tau}\left(w-w_{*}\right)}{1}+\frac{\frac{2 \gamma}{6 \tau}\left(w-w_{*}\right)}{1}+ \\
+\frac{\frac{\frac{2 \gamma}{10 \tau}\left(w-w_{*}\right)}{1}+\cdots+\frac{\frac{n \gamma}{2(2 n-1) \tau}\left(w-w_{*}\right)}{1}+\frac{\frac{n \gamma}{2(2 n+1) \tau}\left(w-w_{*}\right)}{1}+\ldots \cdot(3.19)}{+}+
\end{gathered}
$$

Since

$$
\lim _{n \rightarrow \infty} \frac{n \gamma}{2(2 n-1)\left(\beta+\gamma w_{*}\right)}=\lim _{n \rightarrow \infty} \frac{n \gamma}{2(2 n+1)\left(\beta+\gamma w_{*}\right)}=\frac{\gamma}{4\left(\beta+\gamma w_{*}\right)}
$$

and

$$
\arg \left(\frac{\gamma\left(w-w_{*}\right)}{4\left(\beta+\gamma w_{*}\right)}+\frac{1}{4}\right)=\arg (\beta+\gamma w)-\arg \left(\beta+\gamma w_{*}\right)
$$

then it follows from Theorem 7 that a $\mathrm{T}-\mathrm{CF}$ (3.18) and a $\mathrm{C}-\mathrm{CF}$ (3.19) converge to the function $\ln (\beta+\gamma w)$ in the domain $\mathbf{L}\left(\beta, \gamma, w_{*} ; w\right)$ and on an arbitrary compact set $\mathbf{W} \subset \mathbf{L}\left(\beta, \gamma, w_{*} ; w\right)$ continued fractions converge uniformly.

It follows from (3.2) and (3.3) that this theorem holds.

\section{Conclusions}

The new properties of Thiele reciprocal derivatives which proved in this work allow obtaining a representation of functions of two variables in the form of the product of two continued fractions. This technique can be naturally extended to the case of functions of three, four or more variables. Also, the properties proved in this work together with other properties of Thiele reciprocal derivatives allow us to find the extension of a function $f(\alpha+\beta z)$ from the extension of a function $f(z)$.

\section{References}

1. Корнейчук Н. П. Точные константы в теории приближения. М: Наука, 1987. 424 с.

2. Dzyadyk V.K., Shevchuk I.A. Theory of uniform approximation of functions by polynomials. Berlin-New York: Walter de Gruyter, 2008. 495 p.

3. Уолш Дж. Л. Интерполяция и аппроксимация рациональными функциями в комплексной области. Москва: ИЛ, 1961. 508 с.

4. Корнейчук Н. П. Сплайны в теории приближений. М: Наука, 1984. 352 с.

5. Henrici P. Applied and computational complex Analysis, Volume. 1.: Power series, integration, conformal mapping, location of zeros. New York-London: John Wiley\& Sons, 1974. $697 \mathrm{p}$.

6. Henrici P. Applied and computational complex analysis, Volume. 2.: Special functions, integral transforms, asymptotics, continued fractions.New York-London: John Wiley\& Sons, 1977. $671 \mathrm{p}$.

7. Бейкер (мл.) Дж., Грейвс-Моррис П. Аппроксимации Паде. М: Мир, 1986. 502 с. 
8. Khovanskii A. N. The application of continued fractions and their generalizations to problems in approximation theory. Groningen: P. Noordhoff, 1963. 212 p.

9. Джсонс У.,Трон В. Непрерывные дроби. М.: Мир, 1985. 414 с.

10. Cuyt A., Brevik Petersen V., Verdonk B., Waadeland H., Jones W. B. Handbooks of continued fractions for special functions. Springer, 2008. $447 \mathrm{p}$.

11. Thiele T.N. Interpolationsprechnung. Leipzig: Commisission von B.G. Teubner, 1909. 187 S. .

12. Nörlund N.E. Vorlesungen über Differenzenrechnung. Berlin: Springer, 1924. 560 S.

13. Пагіря M.M. Наближення функцій ланцюговими дробами. - Ужгород: Гражда, 2016. $412 \mathrm{c}$.

14. Бабенко К.И. Основы численного анализа. Москва-Ижевск: НИЦ "Регулярная и хаотическая динамика", 2002. 848 с.

15. Никольский C. М. Приближение функций многих переменных и теоремы вложения. M: Наука, 1977. 456 с.

16. Makarov V.L., Khlobystov V.V., Yanovich L.A. Methods of operator interpolation // Праці I-ту математики НАН України. Т.83. Kyiv, 2010. 517 с.

17. Cuyt A. Pade approximations for operators: Theory and applications. Berlin-Heidelberg: Springeder-Verlag, 1984. $148 \mathrm{p}$.

18. Hildebrand F.B. Introduction to Numerical Analysis. New York: Dover Publications,Inc, 1987. $669 \mathrm{p}$.

19. Milne-Thomson L.M. The Calculus of Finite Differences. Second Edition. Providence, Rhode Island: AMS Chelsea Publishing, American Mathematical Society, 2000. 582 p.

20. Голуб А.П., Чернецька Л.О. Двовимірні узагальнені моментні зображення та раціональні апроксимації функцій двох змінних // Укр. мат. журн. 2013. Т. 65, № 8. С. $1035-1058$.

21. Голуб А.П., Чернецька Л.О. Побудова апроксимант Паде для деяких гіпергеометричних рядів Лаурічелли за допомогою методу узагальнених моментних зображень // Збір. праць Ін-ту математики НАН України, 2014, Т.1, № 1. С. 63-88

22. Скоробогатько В.Я. Теория ветвящихся цепных дробей и ее применение в вычислительной математике. М.: Наука, 1983. 312 с.

23. Кучмінсъка Х.Й. Двовимірні неперервні дроби. Львів: Інститут прикладних проблем механіки і математики ім. Я.С. Підстригача НАН України, 2010. 218 с.

24. Боднар Д.И. Ветвящиеся цепные дроби. Київ: Наукова думка, 1986. 176 с.

25. Cuyt A., Verdonk B. Different Technique for the Construction of Multivariate Rational Interpolation and Pade Approximants. Antwerpen: Universitaire Instelling, 1988. 158 p.

Received: 9 января 2020 г.. Accepted: 20.12.2019 